\title{
PERILAKU TENTANG CUCI TANGAN PAKAI SABUN DI MADRASAH IBTIDAIYAH TASWIRUL AFKAR
}

\author{
BEHAVIOR ABOUT HANDWASHING WITH SOAP \\ AT MADRASAH IBTIDAIYAH TASWIRUL AFKAR
}

\section{Dewa Ayu Komang Lisna Trijayanti}

UD. Sedana Jaya, Jl. Ahmad Yani Utara No.466, Peguyangan Kaja, Kec. Denpasar Utara, Kota Denpasar, Bali

E-mail: dewa.ayu.komang-2016@fkm.unair.ac.id

\begin{abstract}
Background: School is one of the important institution to implementing health promotion program. The problem that need to be noticed is low awareness to wash hands with running water and soap among students. Purpose: The aim of this research is to describe knowledge, attitudes, practice, facility availability, and the teacher's role to support handwashing with soap (HWS) habit among students at Madrasah Ibtidaiyah (MI) Taswirul Afkar Surabaya. Methods: This study used observational descriptive method. The population were students in $4^{\text {th }}$ until $6^{\text {th }}$ grade. Results: Results of the study showed that the majority of students (49.1\%) had good knowledge. Regarding the attitudes, the majority of students (66.7\%) had positive attitudes and most of them (78.4\%) had good practices on handwashing with soap. The majority of respondents (56.8\%) get support from teachers such as counseling. The teachers was not always controlling the facility availability of handwashing (94.1\%) and carrying out supervision handwashing with soap practices among students (76.5\%). Based on observations, it is found that washbasin is only available in the schoolyard and four bathroom rooms. Conclusion: Student's knowledge, attitude, and Practice about handwashing with soap in a good category. There is counseling from teachers and there is no control on handwashing facilities.
\end{abstract}

Keywords: knowledge, attitude, practice, facility, teachers, Handwashing with Soap

\begin{abstract}
ABSTRAK
Latar Belakang: Sekolah adalah salah satu institusi penting untuk melaksanakan program promosi kesehatan. Masalah yang perlu diperhatikan dalam pengembangan program promosi kesehatan di sekolah adalah rendahnya kesadaran para siswa untuk mencuci tangan dengan menggunakan air mengalir dan sabun. Tujuan: Penelitian ini bertujuan untuk mengetahui tingkat pengetahuan, sikap, tindakan, ketersediaan sarana cuci tangan pakai sabun dan peran guru dalam mendukung kebiasaan siswa untuk cuci tangan pakai sabun (CTPS) di Madrasah Ibtidaiyah (MI) Taswirul Afkar Surabaya. Metode: Jenis penelitian ini adalah observasional deskriptif. Populasi dalam penelitian ini adalah siswa kelas 4, 5, dan 6. Hasil: Hasil penelitian menunjukkan tingkat pengetahuan siswa tentang cuci tangan pakai sabun termasuk dalam kategori baik $(49,1 \%)$. Sikap siswa terhadap cuci tangan pakai sabun termasuk dalam kategori baik atau positif $(66,7 \%)$ dan tindakan siswa terhadap cuci tangan pakai sabun termasuk dalam kategori baik $(78,4 \%)$. Mayoritas responden $(56,8 \%)$ mendapatkan dukungan dari guru berupa penyuluhan. Selain itu, guru belum berperan dalam melakukan pengontrolan terhadap ketersediaan sarana cuci tangan $(94,1 \%)$ dan guru belum berperan dalam melaksanakan pengawasan terhadap tindakan cuci tangan pakai sabun pada siswa (76,5\%). Berdasarkan hasil observasi diketahui bahwa tempat cuci tangan hanya tersedia di halaman sekolah dan empat ruang kamar mandi. Kesimpulan: Pengetahuan, Sikap dan Tindakan siswa tentang cuci tangan pakai sabun dalam kategori baik. Adanya penyuluhan dari guru dan belum adanya pengontrolan pada sarana cuci tangan.
\end{abstract}

Kata Kunci: pengetahuan, sikap, tindakan, sarana, guru, CTPS 


\section{PENDAHULUAN}

Kesehatan adalah keadaan seseorang yang sempurna baik secara fisik, mental, dan sosial dimana tidak hanya terbebas dari penyakit maupun cacat (WHO, 1948). Paradigma sehat adalah salah satu pandangan dalam pembangunan kesehatan terhadap masalah kesehatan baik makro maupun mikro yang saling terkait dan mempengaruhi lintas sektoral. Makro dapat diartikan bahwa semua sektor dalam hal pembangunan harus memperhatikan dampak baik positif maupun negatif di bidang kesehatan, seperti pengembangan lingkungan dan perilaku sehat. Contoh dari mikro adalah mengutamakan tindakan preventif dan promotif terhadap suatu penyakit (Kemenkes RI, 2016). Salah satu upaya promotif terhadap kesehatan masyarakat adalah promosi kesehatan (Notoatmodjo, 2012).

Promosi kesehatan adalah suatu upaya yang tidak hanya menekankan perubahan pada pengetahuan, sikap, dan tindakan kesehatan, tetapi juga menciptakan perubahan pada lingkungan baik secara fisik maupun non fisik melalui strategi advokasi, bina suasana pemberdayaan masyarakat, dan peran kemitraan (Kholid, 2014). Sekolah adalah salah satu institusi penting untuk melaksanakan program promosi kesehatan (Alamsyah dan Muliawati, 2013). Program Usaha Kesehatan Sekolah (UKS) atau biasa dikenal dengan istilah Trias UKS merupakan salah satu program promosi kesehatan yang terdiri dari pendidikan kesehatan yang berkesinambungan, pelayanan kesehatan di sekolah, dan pembinaan lingkungan sekolah yang sehat (Budiman, 2015).

Setiap sekolah tentu mempunyai kemampuan yang berbeda-beda dalam melaksanakan program promosi kesehatan tersebut. Kemampuan yang dimiliki kurang, maka beberapa masalah pun dapat muncul sesuai dengan situasi atau kondisi yang dihadapi (Kholid, 2014). Hingga saat ini, penyakit menular yang masih mendominasi adalah diare. Penyakit ini disebabkan karena rendahnya kemampuan anak-anak untuk mencuci tangan dengan menggunakan air mengalir dan sabun (WHO, 2014). Kondisi ini dapat mempengaruhi kualitas sumber daya manusia dan menghalangi anak-anak dalam mencapai potensi maksimal mereka (UNICEF Indonesia, 2012).

World Health Organization (WHO) dan United Nations Children's Fund (UNICEF) menjelaskan bahwa jumlah kasus diare yang terjadi di seluruh dunia sekitar dua miliar kasus setiap tahun. Sebagian besar kasus diare terjadi di negara berkembang. Jumlah anak yang meninggal akibat diare yaitu lebih dari 5.000 anak setiap hari dimana sebanyak $78 \%$ terjadi di wilayah Afrika dan Asia Tenggara (World Gastroenterology Organisation, 2012).

Salah satu negara berkembang yang mempunyai masalah kesehatan masyarakat seperti diare adalah Indonesia. Data Profil Kesehatan Indonesia Tahun 2013-2014 menjelaskan bahwa jumlah perkiraan diare di fasilitas kesehatan sebanyak 5.078.830 jiwa dan mengalami peningkatan menjadi 8.713.537 jiwa. Tahun 2015, sebanyak 5.405.235 jiwa dan mengalami peningkatan kembali pada tahun 2016 menjadi 6.897.463 jiwa (Kemenkes RI, 2017). Data Kementerian Kesehatan RI Tahun 2013-2014 menjelaskan bahwa perkiraan kasus diare di fasilitas kesehatan Jawa Timur mengalami peningkatan dari 770.184 jiwa menjadi 824.531 jiwa. Tahun 2015 mengalami penurunan menjadi 49.405 jiwa dan mengalami peningkatan kembali pada tahun 2016 menjadi 1.048.885 jiwa (Kemenkes RI, 2017).

Data Dinas Kesehatan Jawa Timur Tahun 2013-2015, menjelaskan bahwa jumlah perkiraan kasus diare yang terjadi di kota Surabaya tahun 2013-2014 mengalami peningkatan dari 60.278 jiwa menjadi 60.646 jiwa. Tahun 2015-2016 mengalami peningkatan kembali dari 60.960 jiwa menjadi 77.285 jiwa (Dinkes Jawa Timur, 2016). Peningkatan kasus diare tersebut terjadi karena kapasitas individu rendah yang dipengaruhi oleh domain perilaku. Domain perilaku terdiri dari ranah kognitif, afektif, dan psikomotor yang telah mengalami perubahan menjadi pengetahuan, sikap, dan tindakan (Notoatmodjo, 2012).

Penelitian Amareta dan Ardianto (2017) menjelaskan bahwa mayoritas siswa Madrasah Ibtidaiyah Al Badri memiliki pengetahuan yang kurang mengenai cuci tangan pakai sabun. Sebagian besar tindakan atau praktik siswa untuk melakukan cuci tangan pakai juga masih 
kurang. Penelitian lainnya yang dilakukan oleh Kusumawardhani, dkk. (2017) menjelaskan bahwa mayoritas siswa SDN memiliki pengetahuan yang baik mengenai cuci tangan pakai sabun. Seluruh siswa memiliki sikap yang baik dan mayoritas tindakan siswa juga baik terhadap cuci tangan pakai sabun.

Kedua hasil penelitian tersebut dapat disimpulkan bahwa terdapat perbedaan pengetahuan dan tindakan terhadap cuci tangan pakai sabun antara siswa yang bersekolah di Madrasah Ibtidaiyah dengan siswa yang bersekolah di sekolah dasar negeri. Perbedaan pada kedua hasil penelitian tersebut muncul karena petugas kesehatan memberikan penyuluhan kepada siswa SDN. Pihak sekolah telah menyediakan sarana cuci tangan seperti sabun dan air dalam baskom. Guru-guru di Madrasah Ibtidaiyah juga telah memberikan informasi setiap harinya mengenai cuci tangan, namun sekolah belum mempunyai fasilitas cuci tangan. Tindakan cuci tangan tidak akan menjadi kebiasaan jika tidak didukung oleh sarana prasarana yang memadai.

Peran guru juga sangat berpengaruh dalam membentuk perilaku seseorang, selain ketersediaan sarana (Notoatmodjo, 2012). Hasil observasi awal yang telah dilakukan di Madrasah Ibtidaiyah (MI) Taswirul Afkar diketahui bahwa tidak tersedia sabun pada tempat cuci tangan. Para siswa mencuci tangan hanya menggunakan air mengalir sehingga warga sekolah khususnya siswa berpotensi terkena penyakit seperti diare.

Hasil wawancara dengan lima orang siswa dan dua orang pembina Usaha Kesehatan Sekolah (UKS) dilakukan di Madrasah Ibtidaiyah (MI) Taswirul Afkar Surabaya dijelaskan bahwa para siswa mengetahui dampak positif dan negatif dalam melakukan cuci tangan pakai sabun (CTPS). Kebiasaan mencuci tangan tanpa menggunakan sabun dan kadang-kadang tidak mencuci tangan karena tidak tersedianya sarana cuci tangan seperti sabun. Pembina Usaha Kesehatan Sekolah (UKS) menjelaskan bahwa faktor penghambat bagi siswa untuk melakukan cuci tangan pakai sabun (CTPS) adalah tidak adanya bantuan dana.

Berdasarkan beberapa hal diatas, tujuan dari penelitian ini adalah untuk mengetahui gambaran domain perilaku (tingkat pengetahuan, sikap, dan tindakan), ketersediaan sarana cuci tangan pakai sabun, dan peran guru dalam mendukung kebiasaan siswa untuk cuci tangan pakai sabun di Madrasah Ibtidaiyah (MI) Taswirul Afkar Surabaya.

\section{METODE}

Jenis penelitian ini adalah observasional deskriptif. Penelitian ini dilakukan di Madrasah Ibtidaiyah (MI) Taswirul Afkar Surabaya pada tanggal 01-20 November 2017. Populasi dalam penelitian ini adalah siswa kelas 4, 5, dan $6 \mathrm{Ml}$ Taswirul Afkar yang berjumlah 51 orang. Penelitian ini mengambil seluruh jumlah populasi tersebut tanpa menarik sampel penelitian sebagai unit observasi atau disebut dengan teknik sensus.

Variabel dalam penelitian ini adalah pengetahuan, sikap, tindakan, ketersediaan sarana cuci tangan pakai sabun, dan peran guru dalam mendukung kebiasaan siswa dalam mencuci tangan pakai sabun di Madrasah Ibtidaiyah (MI) Taswirul Afkar Surabaya.

Pengolahan data yang digunakan adalah data primer dengan menggunakan instrumen penelitian. Instrumen penelitian yang digunakan adalah kuesioner, checklist, dan pedoman wawancara. Kuesioner A tentang identitas responden, kuesioner B berisi 16 pertanyaan terkait tingkat pengetahuan siswa tentang cuci tangan pakai sabun (CTPS), kuesioner $\mathrm{C}$ berisi 10 pertanyaan terkait sikap siswa terhadap cuci tangan pakai sabun (CTPS), kuesioner D berisi 12 pertanyaan terkait tindakan siswa terhadap cuci tangan pakai sabun (CTPS), checklist berisi pernyataan tentang ketersediaan sarana seperti dipasangi kran atau lainnya dan kelengkapan cuci tangan seperti sabun, dan pedoman wawancara ketersediaan sarana dan pelaksanaan cuci tangan pakai sabun di sekolah. Analisis data yang dilakukan adalah analisis deskriptif berdasarkan tabel atau gambar grafik.

\section{HASIL DAN PEMBAHASAN}

Berdasarkan hasil penelitian yang telah dilakukan, diketahui bahwa karakteristik responden meliputi umur dan jenis kelamin, pernah atau tidaknya mendapat 
informasi tentang cuci tangan pakai sabun (CTPS), sumber informasi CTPS, tingkat pengetahuan, sikap dan tindakan terhadap CTPS pada siswa Madrasah Ibtidaiyah (MI), ketersediaan sarana CTPS, dan peran guru dalam mendukung kebiasaan siswa untuk cuci tangan pakai sabun di Madrasah Ibtidaiyah (MI) Taswirul Afkar Surabaya.

\section{Tingkatan Kelas dan Jenis Kelamin}

Tabel 1. Karakteristik Responden Berdasarkan Umur dan Jenis Kelamin Siswa Madrasah Ibtidaiyah (MI) Taswirul Afkar Surabaya Tahun 2017

\begin{tabular}{lcc}
\hline \multicolumn{1}{c}{ Karakteristik } & Frekuensi & $\%$ \\
\hline Tingkatan Kelas & & \\
IV & 11 & 21,5 \\
V & 30 & 58,9 \\
VI & 10 & 19,6 \\
Total & 51 & 100 \\
\hline Jenis Kelamin & & \\
Laki-laki & 51 & 100 \\
Perempuan & 0 & 0 \\
Total & 51 & 0 \\
\hline
\end{tabular}

Hasil penelitian menunjukkan bahwa mayoritas responden kelas $\mathrm{V}$ sebanyak 30 orang $(58,9 \%)$ dan seluruh responden sebanyak 51 orang berjenis kelamin lakilaki (100\%) pada siswa MI Taswirul Afkar Surabaya. Seluruh responden berjenis kelamin laki-laki karena penelitian ini dilakukan pada pagi hari sesuai dengan kesepakatan pihak sekolah. Sekolah MI Taswirul Afkar Surabaya memiliki kebijakan bahwa kelas pagi diisi oleh siswa laki-laki dan kelas siang diisi oleh siswa perempuan.

\section{Paparan terhadap Informasi Cuci Tangan Pakai Sabun (CTPS)}

Hasil penelitian menunjukkan bahwa siswa yang pernah mendapat informasi tentang cuci tangan pakai sabun sebanyak 51 orang $(100 \%)$.

\section{Sumber Informasi tentang Cuci Tangan Pakai Sabun (CTPS)}

Hasil penelitian menunjukkan bahwa mayoritas responden mendapatkan informasi dari petugas kesehatan sebanyak 23 orang $(45,1 \%)$.
Tabel 2. Karakteristik Responden Berdasarkan Pernah Mendapat Informasi tentang CTPS pada Siswa Madrasah Ibtidaiyah (MI) Taswirul Afkar Surabaya Tahun 2017

\begin{tabular}{lcl}
\hline \multicolumn{1}{c}{ Karakteristik } & Frekuensi & $\%$ \\
\hline Pernah Mendapat & Informasi & \\
Ya & 51 & 100 \\
Tidak & 0 & 0 \\
Total & 51 & 100 \\
\hline
\end{tabular}

Tabel 3. Karakteristik Responden Berdasarkan Sumber Informasi tentang CTPS pada Siswa Madrasah Ibtidaiyah (MI) Taswirul Afkar Surabaya Tahun 2017

\begin{tabular}{lcc}
\hline Sumber Informasi & Frekuensi & $\%$ \\
\hline Koran/majalah & 1 & 2 \\
TV/radio & 2 & 3,9 \\
Orang tua & 6 & 11,8 \\
Saudara kandung & 3 & 5,9 \\
Petugas kesehatan & 23 & 45,1 \\
Teman & 11 & 21,5 \\
Guru & 5 & 9,8 \\
Sumber informasi & 0 & 0 \\
lain-lain & & \\
Total & 51 & 100 \\
\hline
\end{tabular}

Tingkat Pengetahuan Siswa tentang Cuci Tangan Pakai Sabun (CTPS)

Tabel 4. Karakteristik Frekuensi Tingkat Pengetahuan Siswa Madrasah Ibtidaiyah (MI) Taswirul Afkar Surabaya Tentang Cuci Tangan Pakai Sabun (CTPS) Tahun 2017

\begin{tabular}{lcc}
\hline \multicolumn{1}{c}{$\begin{array}{c}\text { Tingkat } \\
\text { Pengetahuan } \\
\text { Responden }\end{array}$} & Frekuensi & $\%$ \\
\hline Baik & 25 & 49 \\
Cukup & 24 & 47,1 \\
Kurang & 2 & 3,9 \\
Total & 51 & 100 \\
\hline
\end{tabular}

Hasil penelitian menunjukkan bahwa mayoritas tingkat pengetahuan responden adalah baik sebanyak 25 orang $(49,1 \%)$. Hasil wawancara dengan kepala sekolah dijelaskan bahwa sekolah belum memberikan mata pelajaran tambahan mengenai Perilaku Hidup Bersih dan

\section{Jurnal Promkes}


Sehat (PHBS) kepada para siswa, namun petugas kesehatan dari Puskesmas terdekat memberikan informasi terkait kesehatan. Petugas Puskesmas memberikan informasi dengan topik yang berbeda-beda ke sekolah setiap sebulan sekali.

Pengetahuan adalah hasil mengetahui dan mengingat tentang suatu obyek atau hal yang terjadi pada individu dengan memanfaatkan sistem indera dan modal seseorang untuk melakukan suatu tindakan (Notoatmodjo, 2012). Pengetahuan atau ingatan tersebut terbentuk melalui proses belajar dengan pemberian berbagai informasi (Subaris, 2016).

Informasi CTPS yang diberikan kepada responden berasal dari petugas kesehatan. Selain dari petugas kesehatan, informasi tersebut juga diperoleh responden dari teman, orang tua, maupun gurunya. Hal tersebut selaras dengan yang dikemukakan oleh Subaris (2016), bahwa pengetahuan seseorang dapat diperoleh melalui pendidikan atau proses belajar, pengalaman diri sendiri maupun orang lain, dan media yang selanjutnya akan disimpan dalam memori ingat melalui panca indranya.

Faktor-faktor yang mempengaruhi pengetahuan adalah faktor internal dan eksternal. Faktor internal terdiri dari minat, kondisi fisik, dan inteligensia, sedangkan faktor eksternal diantaranya keluarga, masyarakat, dan sarana (Achmadi, 2014). Inteligensia atau kemampuan berpikir tiap orang berbeda-beda. Hal tersebut dapat dipengaruhi oleh berbagai faktor.

Salah satu faktor yang mempengaruhi tingkat pengetahuan siswa mengenai PHBS adalah belum adanya mata pelajaran tentang PHBS di sekolah. Hal tersebut dibuktikan dengan masih ditemukannya dua orang siswa yang memiliki tingkat pengetahuan kurang $(3,9 \%)$. Dukungan informasi dari petugas kesehatan, teman, orang tua, dan guru juga dapat menyebabkan tingkat pengetahuan siswa mengenai CTPS dalam kategori baik $(49,1 \%)$.

Penelitian Kurniatillah (2017) menyatakan bahwa pemberian penyuluhan tentang CTPS dapat meningkatkan pengetahuan siswa kelas V SDN Taman Kota Serang Tahun 2016 dimana peningkatan pengetahuan sebelum dan sesudah diberikan penyuluhan sebesar 43,3\% dengan kategori baik. Hasil penelitian tersebut juga sesuai dengan penelitian Sekarwati (2017) yang menjelaskan bahwa pemberian pendidikan kesehatan mampu meningkatkan pengetahuan siswa kelas III SDN Kalasan 1 Sleman Yogyakarta Tahun 2017 dengan peningkatan pengetahuan sebelum dan sesudah diberikan pendidikan sebesar $32,8 \%$.

Pengetahuan yang baik mengenai cuci tangan pakai sabun harus dilandasi dengan pendidikan kesehatan. Pendidikan kesehatan tersebut tidak hanya memberikan fakta tentang risiko dan tindakan yang memperburuk kesehatan, tetapi pengetahuan tersebut juga dapat mengantarkan seseorang agar mengalami perubahan perilaku (UNICEF, 2012).

\section{Sikap Siswa Terhadap Cuci Tangan Pakai Sabun (CTPS)}

Tabel 5. Karakteristik Frekuensi Sikap Siswa Madrasah Ibtidaiyah (MI) Taswirul Afkar Surabaya terhadap Cuci Tangan Pakai Sabun (CTPS) Tahun 2017

\begin{tabular}{lcc}
\hline $\begin{array}{c}\text { Sikap } \\
\text { Responden }\end{array}$ & Frekuensi & $\%$ \\
\hline Positif & 34 & 66,7 \\
Negatif & 17 & 33,3 \\
Total & 51 & 100 \\
\hline
\end{tabular}

Hasil penelitian menunjukkan bahwa mayoritas sikap responden adalah positif sebanyak 34 orang $(66,7 \%)$. Sikap adalah daya pendorong untuk bertindak atau merespons suatu stimulus atau obyek yang timbul dari perkembangan dan pengalaman individu. Sikap seseorang dikatakan positif apabila suka terhadap suatu objek psikologi atau sikap yang favorable. Sikap seseorang dikatakan negatif apabila ia tidak suka terhadap objek psikologi atau sikap yang unfavorable (Subaris, 2016). Sikap positif memiliki kecenderungan tindakan mendekati atau mendukung dan sikap negatif kecenderungan untuk menjauhi atau tidak mendukung.

Hasil kuesioner tentang paparan dan sumber informasi diperoleh bahwa mayoritas responden mendapatkan penyuluhan tentang CTPS dari petugas kesehatan. Informasi tentang CTPS yang telah didengar dan dipahami oleh para 
siswa akan membentuk pengetahuan. Pengetahuan tersebut akan membuat siswa untuk berpikir dan berusaha agar mencuci tangan dengan air mengalir dan sabun. Komponen emosi dan keyakinan yang terdapat dalam pikiran para siswa akan mampu menciptakan niat siswa untuk mencuci tangan pakai sabun, oleh karena itu para siswa tersebut mempunyai sikap tertentu terhadap obyek yang berupa cuci tangan pakai sabun (Notoatmodjo, 2012).

Percaya, ide dan konsep terhadap suatu obyek, kehidupan emosional atau evaluasi terhadap hal (obyek), dan cenderung untuk melakukan tindakan dalam menghadapi obyek adalah tiga komponen utama dalam membentuk sikap utuh. Selain pengetahuan, pikiran, keyakinan dan emosi juga merupakan peranan penting dalam pembentukan sikap yang utuh (Notoatmodjo, 2012). Jika tidak dilandasi dengan keyakinan dan emosi, maka timbul sikap negatif terhadap CTPS. Hal tersebut dibuktikan dengan ditemukannya sikap negatif pada 17 orang $(33,3 \%)$ siswa.

\section{Tindakan Siswa Terhadap Cuci Tangan Pakai Sabun (CTPS)}

Tabel 6. Karakteristik Frekuensi Tindakan Siswa Madrasah Ibtidaiyah (MI) Taswirul Afkar Surabaya Terhadap Cuci Tangan Pakai Sabun (CTPS) Tahun 2017

\begin{tabular}{lcc}
\hline $\begin{array}{c}\text { Tindakan } \\
\text { Responden }\end{array}$ & Frekuensi & $\%$ \\
\hline Baik & 40 & 78,5 \\
Cukup & 9 & 17,6 \\
Kurang & 2 & 3,9 \\
Total & 51 & 100 \\
\hline
\end{tabular}

Hasil penelitian menunjukkan bahwa mayoritas tindakan responden terkait kebiasaan cuci tangan pakai sabun adalah baik sebanyak 40 orang $(78,4 \%)$. Hasil wawancara yang telah dilakukan pada siswa menyatakan bahwa kebiasaan siswa dalam mencuci tangan pakai sabun biasanya diterapkan di rumah. Hal tersebut karena tersedia air bersih dan sabun di rumah, sedangkan bila di sekolah, siswa juga melakukan cuci tangan tetapi tidak menggunakan sabun.

Tindakan adalah aksi nyata dari seseorang terhadap stimulus atau rangsangan dari luar subyek yang dapat diamati dan dipelajari oleh orang lain (Kholid, 2014). Tindakan juga merupakan respon seseorang terhadap stimulus tertentu yang dapat dibentuk maupun diubah sesuai dengan proses di dalam tubuhnya (Achmadi, 2014). Kebiasaan adalah kegiatan atau tindakan tetap yang dilakukan seseorang secara berulang-ulang untuk hal yang sama apabila tidak ada perubahan dalam situasi yang dihadapinya (Notoatmodjo, 2014). Kebiasaan atau perilaku tersebut dapat dipengaruhi oleh pengetahuan, sikap, ketersediaan sarana cuci tangan pakai sabun, dan peran guru di sekolah (Notoatmodjo, 2012).

Hasil penelitian mengenai tindakan siswa tersebut sesuai dengan teori Notoatmodjo (2012) yang menjelaskan bahwa tindakan seseorang dalam menghadapi masalah dapat terbentuk karena adanya dasar berupa pengetahuan. Pengetahuan yang dimiliki akan mengakibatkan orang tersebut mengetahui stimulus yang diberikan, kemudian memberikan penilaian terhadap stimulus tersebut dan melaksanakan apa yang diketahui atau disikapinya. Hasil penelitian ini juga sesuai dengan teori Subaris (2016) yang menyatakan bahwa pengetahuan yang telah didapatkan sebelumnya menyebabkan seseorang mulai berpikir, kemudian timbul kesiapan seseorang untuk bertindak, dan akhirnya termotivasi untuk melakukan suatu tindakan.

Domain perilaku bertujuan untuk mendukung tujuan pendidikan yang dibagi menjadi tiga ranah yaitu ranah kognitif (kognitif domain), ranah afektif (affectife domain), dan ranah psikomotor (psychomotor domain) (Notoatmodjo, 2012). Ranah kognitif menekankan aspek intelektual seperti pengetahuan. Ranah afektif berkaitan dengan emosi seperti sikap dan ranah psikomotorik yang menekankan keterampilan fisik atau motorik seperti perilaku (Achmadi, 2014).

Berkaitan dengan perilaku, Rogers dalam Notoatmodjo (2012) menyatakan bahwa sebelum mengadopsi perilaku, seseorang akan mengalami beberapa proses di dalam dirinya yaitu kesadaran, tertarik, evaluasi, mencoba, dan menerima atau disingkat AIETA. Sebagian besar siswa MI Taswirul Afkar sudah mengalami 4 proses adopsi perilaku yang terdiri dari kesadaran 
(awareness), tertarik (interest), evaluasi (evaluation), dan adopsi (adoption). Proses adopsi yang pertama adalah kesadaran (awareness) yaitu siswa mengetahui, memahami, dan menyadari pentingnya cuci tangan pakai sabun (CTPS). Kedua adalah tertarik (interest) yaitu mulai tertarik untuk mengetahui secara lanjut tentang cuci tangan pakai sabun (CTPS). Ketiga adalah evaluasi (evaluation) yaitu siswa menimbang baik buruknya mencuci tangan. Keempat adalah adopsi (adoption) yaitu mulai mencoba untuk melakukan cuci tangan pakai sabun (CTPS).

Siswa sudah mencapai proses menerima dimana siswa memiliki kebiasaan cuci tangan yang baik tetapi kebiasaan tersebut tidak dilaksanakan di sekolah karena hanya tersedia air mengalir melalui kran dan tidak tersedia sabun. Selain itu, tindakan yang tidak didasari oleh inteligensia yang baik tentu akan

\begin{tabular}{|c|c|c|c|}
\hline & $\begin{array}{c}\text { Cognitiv } \\
\text { e }\end{array}$ & $\begin{array}{l}\text { Affecti } \\
\text { ve }\end{array}$ & $\begin{array}{c}\text { Psychomoto } \\
r\end{array}$ \\
\hline $1950 \mathrm{~s}$ & \multirow{3}{*}{$\begin{array}{l}\text { Bloom } \\
\text { s et al } \\
(1956) \\
\text { Cognit } \\
\text { ive }\end{array}$} & \multirow{3}{*}{$\begin{array}{c}\text { Bloom } \\
\text { s et al } \\
(1956) \\
(1964) \\
\text { Affecti } \\
\text { ve }\end{array}$} & \multirow{4}{*}{$\begin{array}{c}\text { Bloom(195 } \\
\text { 6) Dave } \\
\text { (1967/70); } \\
\text { Simpson } \\
\text { (1966/72); } \\
\text { Harrow } \\
\text { (1972) } \\
\text { Psychomo } \\
\text { tor }\end{array}$} \\
\hline & & & \\
\hline \multirow[t]{3}{*}{ 1960s } & & & \\
\hline & & \multirow{3}{*}{$\begin{array}{c}\text { Krath } \\
\text { wohl's } \\
\text { et al } \\
(1964) \\
\text { Affecti } \\
\text { ve }\end{array}$} & \\
\hline & & & \multirow{2}{*}{$\begin{array}{c}\text { Dave } \\
\text { (1970) } \\
\text { Psycho } \\
\text { motor }\end{array}$} \\
\hline 1970s & & & \\
\hline 1980s & $\begin{array}{c}\text { Biggs \& } \\
\text { Collis } \\
(1982)\end{array}$ & & \\
\hline \multirow[t]{2}{*}{ 1990s } & & & \\
\hline & Anderso & & \\
\hline \multirow[t]{3}{*}{$\begin{array}{l}2000- \\
10\end{array}$} & $\begin{array}{l}\text { n et al } \\
(2001)\end{array}$ & & \\
\hline & $\vee$ & & \\
\hline & Fink & 003) & \\
\hline
\end{tabular}

Sumber : O’Neill dan Murphy, 2010

Gambar 1. Perkembangan Taksonomi dan Domain berdampak pada tingkat pengetahuan dan sikapnya. Hal tersebut telah dibuktikan dengan masih ditemukannya tindakan yang kurang baik $(3,9 \%)$ pada dua orang siswa yang memiliki tingkat pengetahuan yang kurang baik $(3,9 \%)$.

\section{Ketersediaan Sarana Cuci Tangan Pakai Sabun (CTPS)}

Hasil observasi dengan menggunakan checklist, diketahui bahwa ketersediaan sarana cuci tangan pakai sabun (CTPS) termasuk dalam kategori kurang baik karena hanya tersedia sarana berupa kran dengan air mengalir tanpa dilengkapi dengan sabun. Ketersediaan sarana CPTS baik apabila di sekolah terdapat sarana dan kelengkapan cuci tangan. Selain itu, tempat cuci tangan hanya tersedia di halaman sekolah dan 4 ruang kamar mandi.

Di halaman sekolah, terdapat kran dengan air mengalir sebanyak 6 buah dan di masing-masing kamar mandi sebanyak 4 buah. Sarana cuci tangan lainnya seperti sabun tidak tersedia baik di halaman sekolah maupun di masing-masing kamar mandi. Tempat cuci tangan yang berada di depan ruang kelas di lantai dua sudah tidak beroperasi lagi.

Keputusan Menteri Kesehatan Republik Indonesia Nomor 1429/MENKES/SK/XII/ 2006 dijelaskan bahwa setiap sekolah harus memiliki beberapa ruang kelas yang menyediakan tempat cuci tangan dengan air bersih yang mengalir di depan ruang kelas. Jumlah minimal tempat cuci tangan adalah satu untuk dua kelas. Sekolah juga harus menyediakan sabun cuci tangan di toilet. Berdasarkan kebijakan tersebut, sekolah belum menyediakan tempat cuci tangan di depan ruang kelas dan sabun untuk cuci tangan di masing-masing kamar mandi (toilet) sekolah.

Hasil wawancara dengan pembina Usaha Kesehatan Sekolah (UKS), menyatakan bahwa faktor penghambat dalam pelaksanaan cuci tangan pakai sabun adalah tidak adanya bantuan dana untuk mendukung ketersediaan sarana cuci tangan seperti sabun. Ketersediaan sarana merupakan salah satu faktor yang mempengaruhi dan memperkuat terbentuknya perilaku seseorang (Kholid, 2014). Tidak tersedianya sarana cuci tangan 
pakai sabun maka akan mempengaruhi kebiasaan siswa.

Peraturan Menteri Pendidikan Nasional Republik Indonesia Nomor 24 Tahun 2007 dijelaskan bahwa kapasitas minimum ruang kelas sebanyak 28 peserta didik, dimana setiap ruang terdapat 1 buah tempat cuci tangan. Berdasarkan kebijakan tersebut, sekolah belum menjalankan peraturan tersebut. Sekolah hanya menyediakan tempat cuci tangan di halaman sekolah dan hanya terdapat sarana berupa air mengalir.

Water, Sanitation and Hygiene Standars for School in Low-cost Settings (2009) menjelaskan bahwa semua titik di sekolah terutama toilet harus menyediakan fasilitas dan akses terhadap air bersih dengan indikator air bersih, sabun atau alternatif yang sesuai. Water, Sanitation, and Hygiene (WASH) in School (2012) juga dijelaskan bahwa mencuci tangan menggunakan sabun dapat mengurangi risiko (42-48\%) terkena penyakit diare. Hal tersebut juga didukung oleh adanya sarana cuci tangan berupa air bersih, sabun atau alternatif lainnya, namun berdasarkan hasil observasi yang telah dilakukan, MI Taswirul Afkar hanya memenuhi satu syarat sarana cuci tangan pakai sabun yaitu air mengalir.

Ketersediaan sarana cuci tangan pakai sabun yang kurang memadai baik kualitas maupun kuantitasnya juga dapat menyebabkan suatu sekolah menjadi lingkungan yang berisiko tinggi bagi anak-anak untuk menularkan penyakit diare (WHO, 2009). Suatu intervensi promosi kesehatan seperti cuci tangan pakai sabun harus memperhatikan dan sebelumnya mendiagnosis faktor ketersediaan sarana disamping pengetahuan, sikap, dan tindakannya. Hal tersebut bertujuan agar perilaku baik individu, kelompok, dan masyarakat yang didukung oleh sarana mempunyai dampak yang positif terhadap pencegahan dan peningkatan kesehatan (Subaris, 2016).

\section{Peran Guru dalam Mendukung Penerapan Cuci Tangan Pakai Sabun Pada Siswa}

Hasil kuesioner diketahui bahwa sebanyak 29 orang (56,8\%) mendapatkan dukungan dari guru berupa penyuluhan mengenai cuci tangan pakai sabun. Mayoritas responden yaitu sebanyak 48 orang $(94,1 \%)$ menyatakan bahwa guru belum berperan dalam melakukan pengontrolan terhadap ketersediaan sarana cuci tangan seperti sabun. Sebanyak 39 orang $(76,5 \%)$ juga menyatakan bahwa guru belum berperan dalam melaksanakan pengawasan terhadap tindakan cuci tangan pakai sabun pada siswa Madrasah Ibtidaiyah (MI) Taswirul Afkar.

Green dalam Notoatmodjo (2012) menyatakan bahwa terbentuknya perilaku yang positif dipengaruhi oleh tiga faktor yaitu faktor prediposisi, faktor pemungkin dan faktor penguat. Faktor predisposisi adalah faktor yang mencakup tingkat pengetahuan dan sikap. Faktor pemungkin adalah faktor yang berkaitan dengan sarana prasarana, seperti air bersih. Faktor penguat adalah sikap dan perilaku dari tokoh masyarakat, tokoh agama, dan lainnya. Guru merupakan salah satu faktor penguat terbentuknya perilaku cuci tangan pakai sabun pada siswa. Para siswa tidak hanya membutuhkan pengetahuan, sikap, tindakan, dan ketersediaan sarana, tetapi mereka juga membutuhkan peran serta guru dalam mendukung tercipatnya kebiasaan cuci tangan pakai sabun.

\section{SIMPULAN}

Hasil penelitian terhadap tingkat pengetahuan, sikap, tindakan, ketersediaan sarana cuci tangan pakai sabun, dan peran guru dalam mendukung kebiasaan untuk cuci tangan pakai sabun pada siswa Madrasah Ibtidaiyah (MI) Taswirul Afkar Surabaya dapat disimpulkan bahwa tingkat pengetahuan siswa tentang cuci tangan pakai sabun (CTPS) termasuk dalam kategori baik sebanyak 25 orang $(49,1 \%)$. Sikap siswa terhadap CTPS adalah positif atau baik sebanyak 34 orang $(66,7 \%)$ dan tindakan siswa terhadap CTPS termasuk dalam kategori baik sebanyak 40 orang $(78,4 \%)$.

Hasil observasi dengan checklist dijelaskan bahwa, sarana CTPS di MI Taswirul Afkar seperti sabun tidak tersedia baik di halaman sekolah maupun di masing-masing kamar mandi. Tempat cuci tangan hanya tersedia di halaman sekolah dan 4 ruang kamar mandi. Berdasarkan hasil kuesioner diketahui bahwa mayoritas responden $(56,8 \%)$ mendapatkan dukungan dari guru berupa penyuluhan mengenai cuci tangan pakai sabun. Guru belum berperan 
J urnal Promkes: The Indonesian J ournal of Health Promotion and Health Education Vol. 7 No. 1 (2019) 46-55. doi: 10.20473/jpk.V7.I1.2019.46-55

dalam melakukan pengontrolan terhadap kelengkapan cuci tangan seperti sabun $(94,1 \%)$, selain itu guru belum berperan dalam melaksanakan pengawasan terhadap tindakan cuci tangan pakai sabun $(76,5 \%)$ pada siswa Madrasah Ibtidaiyah (MI) Taswirul Afkar Surabaya.

\section{DAFTAR PUSTAKA}

Achmadi, Umar. 2014. Kesehatan Masyarakat: Teori dan Aplikasi. Jakarta: Rajawali Pers.

Amareta dan Ardianto. 2017. Peningkatan Praktik Cuci Tangan Pakai Sabun pada Anak Usia Sekolah dengan Metode Emo Demo, Jurnal Kesehatan Lingkungan Vol. 9 No. 2 Tahun 2017: 88-92.

Alamsyah dan Muliawati. 2013. Pilar Dasar Ilmu Kesehatan Masyarakat. Yogyakarta: Nuha Medika.

Budiman. 2015. Buku Ajar Isu Tataran Kesehatan Masyarakat. Bandung: Refika Aditama.

Djarkoni, Lampus, dkk. Hubungan Perilaku Cuci Tangan Pakai Sabun dengan Kejadian Diare di SD Advent Sario Kota Manado, Jurnal Ilmu Kedokteran Komunitas Fakultas Kedokteran Universitas Sam Ratulangi Vol. 2 No. 3 Tahun 2014: 9598.

Dinkes Provinsi Jawa Timur. 2013. Profil Kesehatan Provinsi Jawa Timur 2013. Jawa Timur: Dinas Kesehatan Provinsi Jawa Timur.

Dinkes Provinsi Jawa Timur. 2014. Profil Kesehatan Provinsi Jawa Timur 2014. Jawa Timur: Dinas Kesehatan Provinsi Jawa Timur.

Dinkes Provinsi Jawa Timur. 2015. Profil Kesehatan Provinsi Jawa Timur 2015. Jawa Timur: Dinas Kesehatan Provinsi Jawa Timur.

Dinkes Provinsi Jawa Timur. 2016. Profil Kesehatan Provinsi Jawa Timur 2016. Jawa Timur: Dinas Kesehatan Provinsi Jawa Timur.

Kemenkes RI. 2006. Pedoman Penyelenggaraan Kesehatan Lingkungan Sekolah. Jakarta: Kementerian Kesehatan RI.

Kemenkes RI. 2007. Riset Kesehatan Dasar. Jakarta: Kementerian Kesehatan RI.

Kemenkes RI. 2011. Situasi Diare di Indonesia. Jakarta: Kementerian Kesehatan RI.
Kemenkes RI. 2013. Riset Kesehatan Dasar. Jakarta: Kementerian Kesehatan RI.

Kemenkes RI. 2013. Profil Kesehatan Indonesia Tahun 2013. Jakarta: Kementerian Kesehatan RI.

Kemenkes RI. 2014. Profil Kesehatan Indonesia Tahun 2014. Jakarta: Kementerian Kesehatan RI.

Kemenkes RI. 2015. Profil Kesehatan Indonesia Tahun 2015. Jakarta: Kementerian Kesehatan RI.

Kemenkes RI. 2016. Profil Kesehatan Indonesia Tahun 2016. Jakarta: Kementerian Kesehatan RI.

Kemenkes RI. 2016. Pedoman Indonesia Sehat dengan Pendekatan Keluarga. Jakarta: Kementerian Kesehatan RI.

Kemenkes RI. 2017. Profil Kesehatan Indonesia Tahun 2017. Jakarta: Kementerian Kesehatan RI.

Keputusan Menteri Kesehatan Republik Indonesia Nomor 1429/MENKES/SK/ XII/2006. 2006. Pedoman Penyelenggaraan Kesehatan Lingkungan Sekolah. Jakarta: Kementerian Kesehatan RI.

Kholid, Ahmad. 2014. Promosi Kesehatan dengan Pendekatan Teori Perilaku, Media, dan Aplikasinya. Jakarta: PT Raja Grafindo Persada.

Kuniatillah, Nia. 2017. Pengaruh Penyuluhan PHBS tentang Cuci Tangan Pakai Sabun terhadap Pengetahuan, Sikap, dan Praktik Siswa Kelas V SDN Taman Kota Serang, Falatehan Health Journal Vol. 4 No. 2: 153-157.

Kusumawardhani, Syahati, dkk. 2017. Pengetahuan, Sikap, dan Tindakan Mencuci Tangan Yang Benar pada Siswa Kelas 1 dan Kelas 2 di SDN 2 Karanglo Klaten Selatan, Jurnal Kebidanan dan Kesehatan Tradisional Vol. 2 No. 1 Tahun 2017: 44-50.

Notoatmodjo, Soekidjo. 2012. Promosi Kesehatan dan Perilaku Kesehatan. Jakarta: Rineka Cipta.

Notoatmodjo, Soekidjo. 2014. Ilmu Perilaku Kesehatan. Jakarta: Rineka Cipta.

O’Neill dan Murphy. 2010. Guide to Taxonomies of Learning. Dublin: University College Dublin.

Peraturan Menteri Pendidikan Nasional Republik Indonesia Nomor 24 Tahun 2007. 2007. Standar Sarana dan Prasarana untuk Sekolah Dasar/Madrasah Ibtidaiyah 
(SD/MI), Sekolah Menengah Pertama/ Madrasah Tsanawiyah (SMP/MTs), dan Sekolah Menengah Atas/Madrasah Aliyah (SMA/MA). Jakarta: Menteri Pendidikan Nasional RI.

Priyoto. 2014. Teori Sikap dan Perilaku dalam Kesehatan. Yogyakarta: Nuha Medika.

Sekarwati, Novita. 2017. Pengaruh Pendidikan Kesehatan Terhadap Perilaku Anak Sekolah Tentang Cuci Tangan Pakai Sabun (CTPS) pada Siswa di Sekolah Dasar Negeri Kalasan 1 Kalasan Sleman Yogyakarta, Jurnal Formil (Forum Ilmiah) KesMas Respati Vol. 2 No. 1: 11-16.

Subaris, Heru. 2016. Promosi Kesehatan, Pemberdayaan Masyarakat, dan Norma Sosial. Yogyakarta: Nuha Medika.

United Nations Children's Fund Indonesia. 2012. Air Bersih, Sanitasi, dan Kebersihan. Jakarta: UNICEF Indonesia.
United Nations Children's Fund. 2012. Water, Sanitation and Hygiene (WASH) in Schools. USA: UNICEF.

World Gastroenterology Organisation. 2012. Acute Diarrhea in Adult and Children: A Global Perspective. Milwaukee: World Gastroenterology Organisation dan Global Guidelines and Cascades.

World Health Organization.1948. WHO Definition of Health. Switzerland: WHO Press.

World Health Organization. 2009. Water, Sanitation and Hygiene Standards for Schools in Low-cost Settings. Switzerland: WHO Press.

World Health Organization. 2014. Diarrhoea. Switzerland: WHO Press. 